\title{
The Excellence as a Habit - The Thyroid Repair
}

\author{
Lucian MÂNDREA \\ Politehnica University of Bucharest, Bucharest, Romania \\ mandrea_lucian@hotmail.com,lucian.mandrea@upb.ro \\ Ioan CURTA \\ Transilvania University of Brașov, Brașov, Romania \\ icurta@yahoo.com \\ Aurel CHIRILĂ \\ University Politehnica of Bucharest, Bucharest, Romania \\ aurel.chirila@gmail.com \\ Dragoș DEACONU \\ University Politehnica of Bucharest, Bucharest, Romania \\ dragos.deaconu@gmail.com
}

PICBE | 13

\begin{abstract}
The research shows in the first part that it is possible to maintain a very good state of the human being for a long time, almost continuously. This thing is highlighted using the values of the human being general balance, while the other values are in the optimal range. The measurements were performed by means of a Bio Well device. The tested subject was the first author of this article. Different techniques were used continuously to reach this important goal. Of course, this attitude can only lead to excellence in everyone's activity domain and also, in general, in everybody's life. The second part of the research refers to the human being's possibilities to send energy to the energy cover of the body to improve the human being functioning. This thing is proved by the measurements made with the help of a thermo- vision camera. A short film was made to show the temperature increase at the level of the head skin during five minutes due to the energy arrived at that zone. The third part refers of the possibility of the human beings to repair themselves. The analysis of the thyroid energy level of the measured subject by means of the Bio Well device is presented. Because the thyroid was used a little too much to improve the optimization of the human being functioning, as presented in the first part of this article, the device shows a possible future danger. Immediate measures had to be taken. Due to successive measures, the subject succeeds in bringing his thyroid energy level to a normal one, without the help of medicines. All the three types of the measurements are very original, presented maybe for the first time in the world. The general purpose of the article is to show that we can do more than we believe about our health and our level of performance.
\end{abstract}

Keywords: Excellence, General body balance, Thermo Vision Camera, Bio Well Device, Thyroid.

\section{Introduction}

Our capacity to repair ourselves presented in the previous articles [Mândrea et al., 2015], [Mândrea \& Torp, 2016], [Mândrea \& Chirilă, 2017], [Mândrea et al., 2018], justifies obtaining very good results in terms of health and personal good physical and psychic state. There are also similar investigations performed by researchers correlated with the domain of human resources management as [Torp, 2018].

The first set of three measurements shows the possibility to reach very high levels of personal symmetry or general balance of the body. This personal indicator is a very important one, because if you have asymmetries, from the point of view of the Chinese doctors, you have more chances to become ill. And of course, if your general 
balance will approach $100 \%$, you are almost sure healthy. The measurements were made using a Bio-Well device already presented in [Mândrea et al., 2018].

The second set of measurements presents six infrared pictures of the first author of this article. The first is a general one and the other five show the upper part of the subject head. By analyzing the dynamic of the temperature variation, they prove that, in general, the energy can be send wherever we want in the body and also at the level of the energy shell. This activity's purpose is to obtain a very good and consistent energy cover of the body and a better organ functioning in order to be healthy and full of energy.

The third set of five measurements proves that we can fix ourselves in case future health problems occur and, as an example, we presented the process of the thyroid repair for the article's first author.

\section{Measurements and Results}

As previously showed [Mândrea \& Chirilă, 2017], by applying different methods to improve the general health of a person, a high level of symmetry can be obtained. In our first case, the equilibrium value is of $99.97 \%$, as presented in Figure 1, row three.

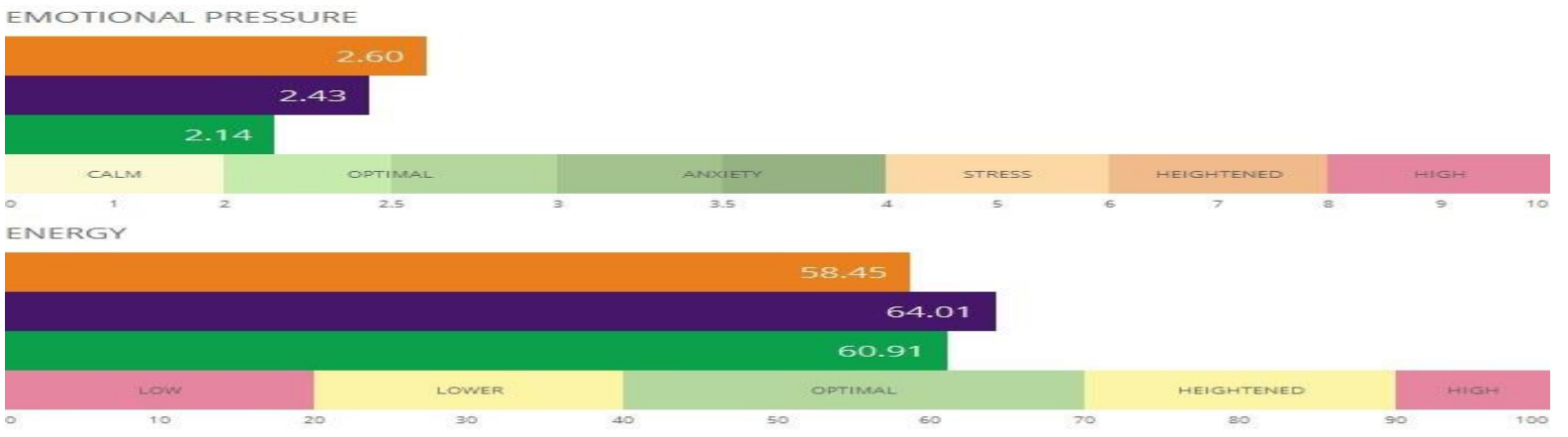

LR SYMMETRY

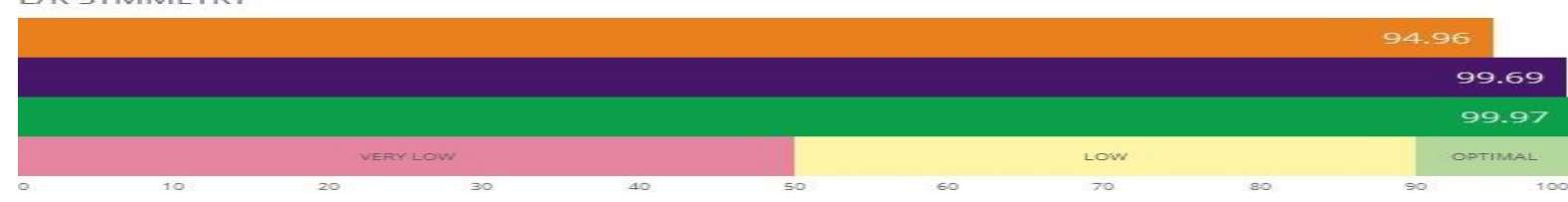

ORGANS BALANCE

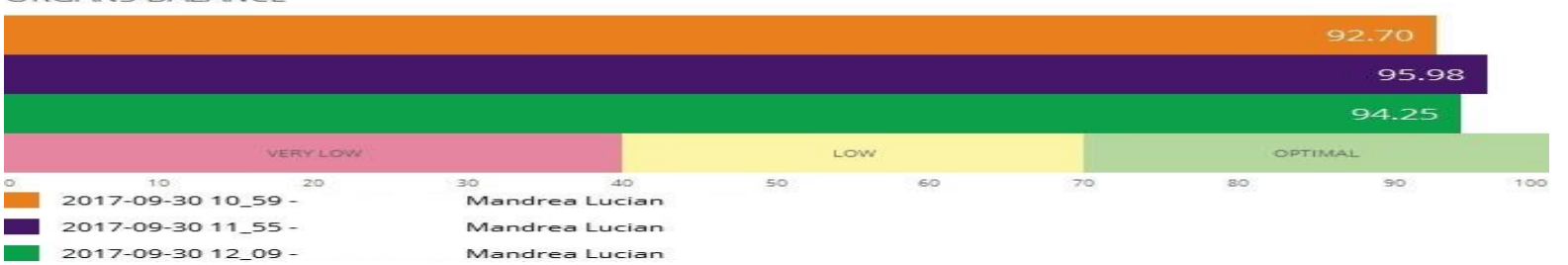

Figure 1. Electro Photonic Imaging Device state data, recorded in September 2017 (The article's first author)

Source: Authors' own research.

By continuously optimizing the body's general functioning, during long periods of time, day by day, the authors show that an almost perfect symmetry can be obtained again, as presented in Figure 2. This time, the symmetry value is of $99.96 \%$ as in the third row. 


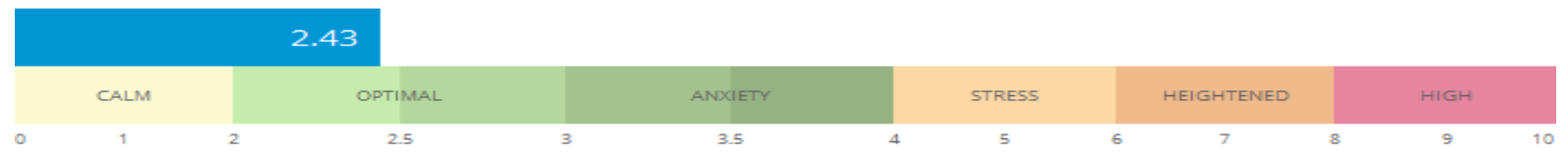

ENERGY: Heightened

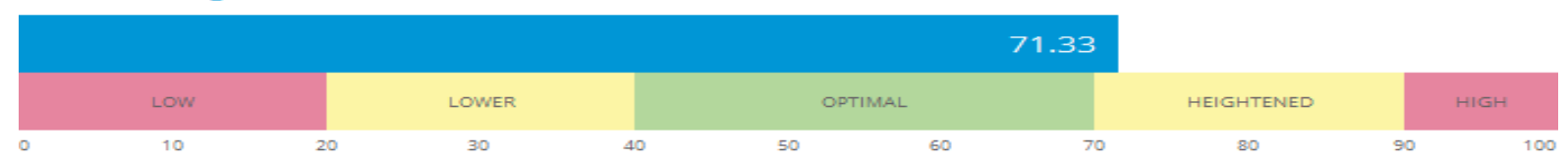

L/R SYMMETRY: Optimal

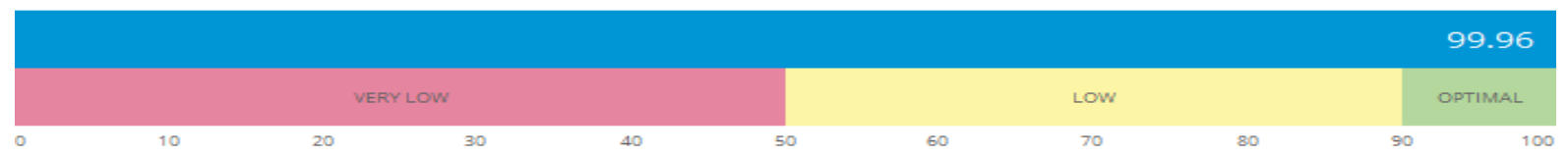

ORGANS BALANCE: Optimal

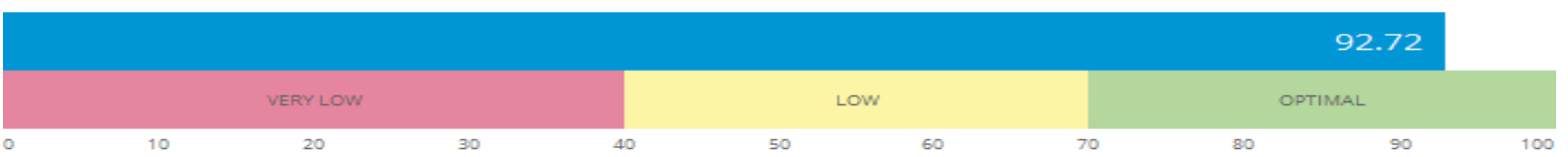

Figure 2. Electro Photonic Imaging Device state data, recorded in January 6, 2018 (The article's first author)

Source: Authors' own research.

At an interval of 12 days, the things repeated, as presented in Figure 3. We can conclude that we can be optimistic referring to the level of health, if we see that the others parameters are also in the green zone, as they should be. More than that, the subject's energy is increased, being heightened to 71.33 as in Figure 2, or optimal to heightened, with the value of 67.24, as in Figure 3.

EMOTIONAL PRESSURE: Optimal

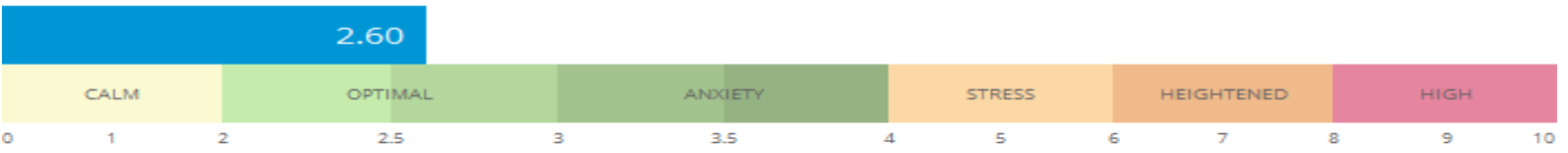

ENERGY: Optimal

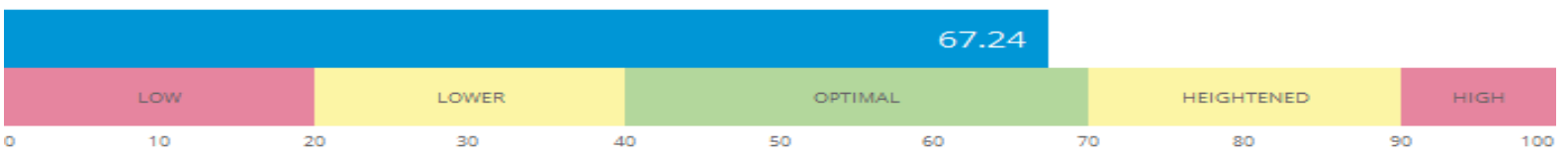

L/R SYMMETRY: Optimal

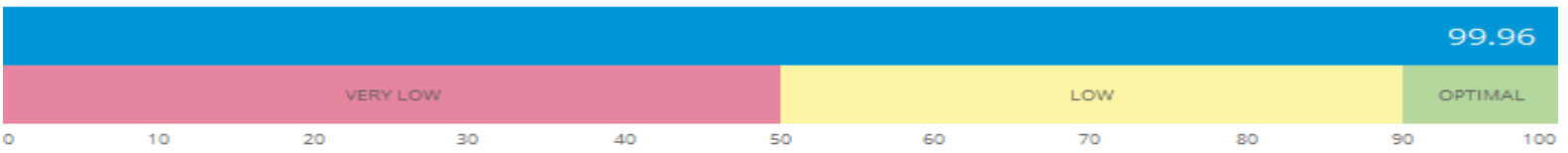

ORGANS BALANCE: Optimal

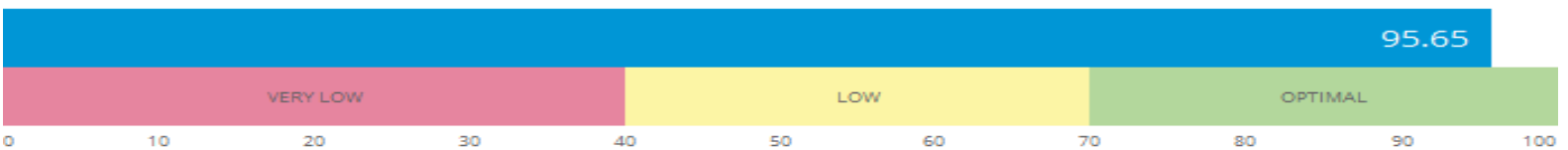

Figure 3. Electro Photonic Imaging Device state data, recorded in January 27, 2018 (The article's first author)

Source: Authors' own research.

We just showed that to reach perfection is not a random thing. It is certitude.

The second part of our article presents other new measurements using this time a Thermo Vision Camera Fluke TI 300. The thermal sensitivity (NETD / Noise Equivalent 
Temperature Difference) of the camera is $\leq 0.05{ }^{\circ} \mathrm{C}$ at $30{ }^{\circ} \mathrm{C}(50 \mathrm{mK})$. The measurement domain is $-20^{\circ} \mathrm{C} \ldots+650{ }^{\circ} \mathrm{C}$ and the image resolution is $240 \times 180$ pixels [Fluke, 2013].

This presentation represents a new research, taking into account our old publications in this domain of temperature registration [Mândrea et al., 2015], [Mândrea, 2014].

The general aspect of the analyzed subject before the experiment, the first author of the article, is presented in Figure 4, which reveals cold and warm body zones.

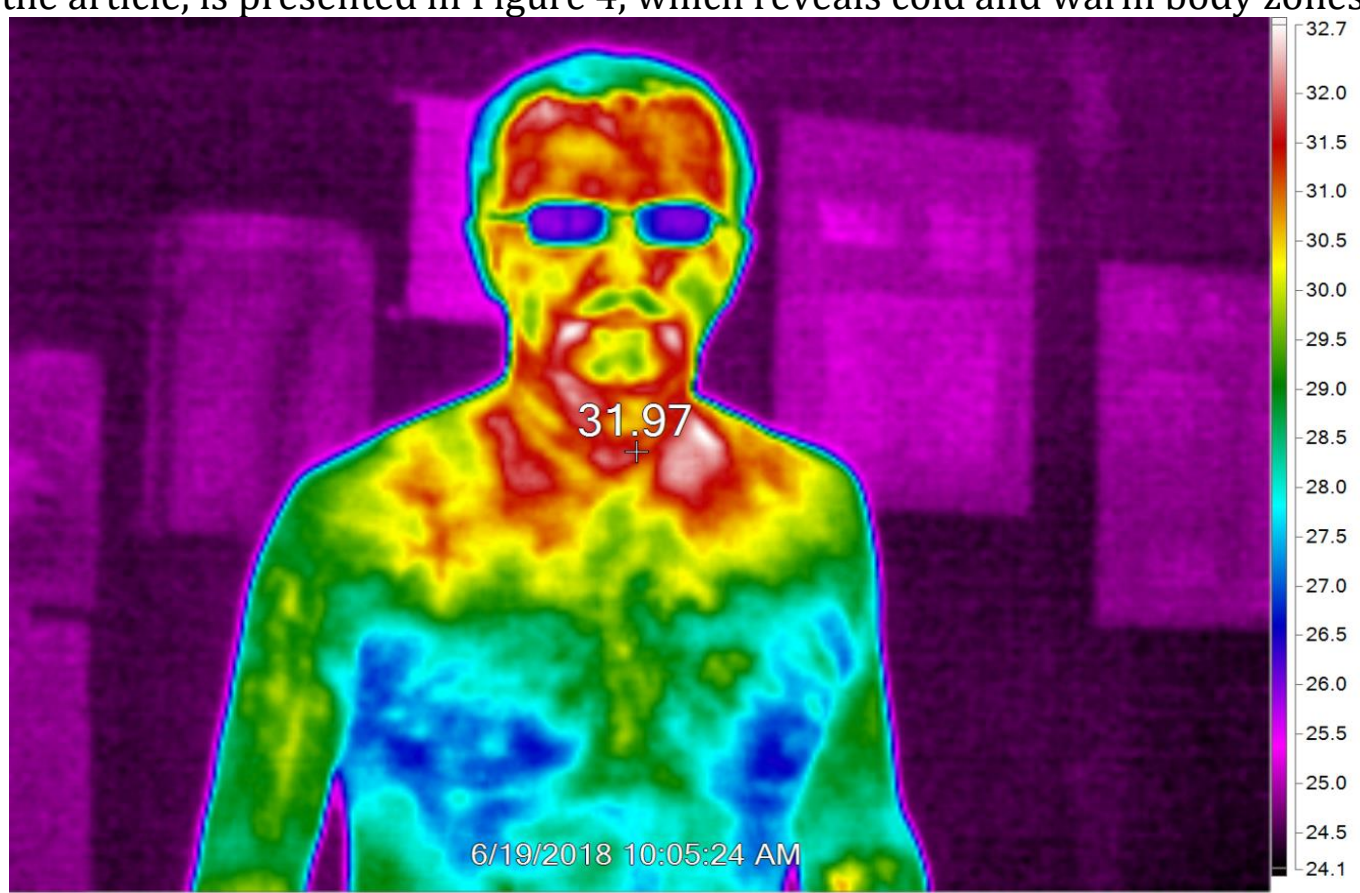

Figure 4. Global Thermo vision Camera state data, 2018

(The article's first author)

Source: Authors' own research.

This is a usual state of the subject. It has nothing special at the beginning, the images being taken in the subject's personal office at the university during working hours. The subject took, then, a sophisticate action to send the energy to the upper part of his head. The energy was sent simultaneously from the energy center number 2 along the main interior energy vertically high ward to the body through the energy center number 7 and, also, around the energy cover of the body.

The effect of this simultaneous sending of the energy is the temperature increase of the head upper part by approximately 3 degrees in 5 minutes, without moving. As a consequence, the blue and green colors from the second image, which is Figure 5, are replaced with the yellow and red colors as can be seen in the images 3 to 6 , which correspond to Figures 6 to 9. It is very probably a unique experiment in the world due to the way of increasing the energy and also due to the value of the temperature growth in a short time. This experiment proves that we can maintain a very good energetic cover of the body and, also, that we can send beams of energy to every organ to repair it in order to function better. Therefore, with the help of our own well used energy, we can maintain ourselves healthy and we can create in ourselves a very good physical and psychic state, for as long as possible. 


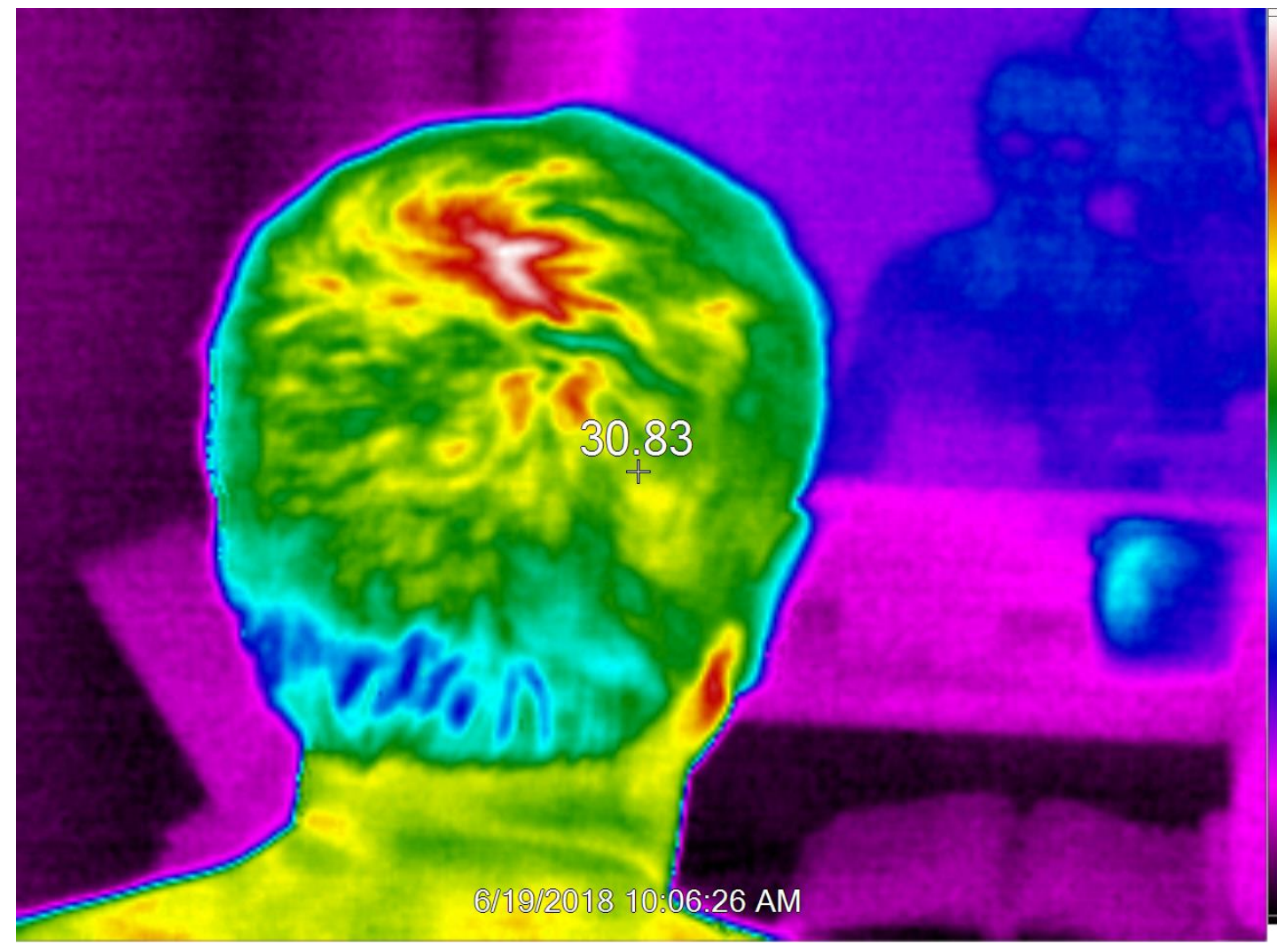

Figure 5. First upper part of the head Thermo vision Camera state data, 2018 (The article's first author)

Source: Authors' own research.

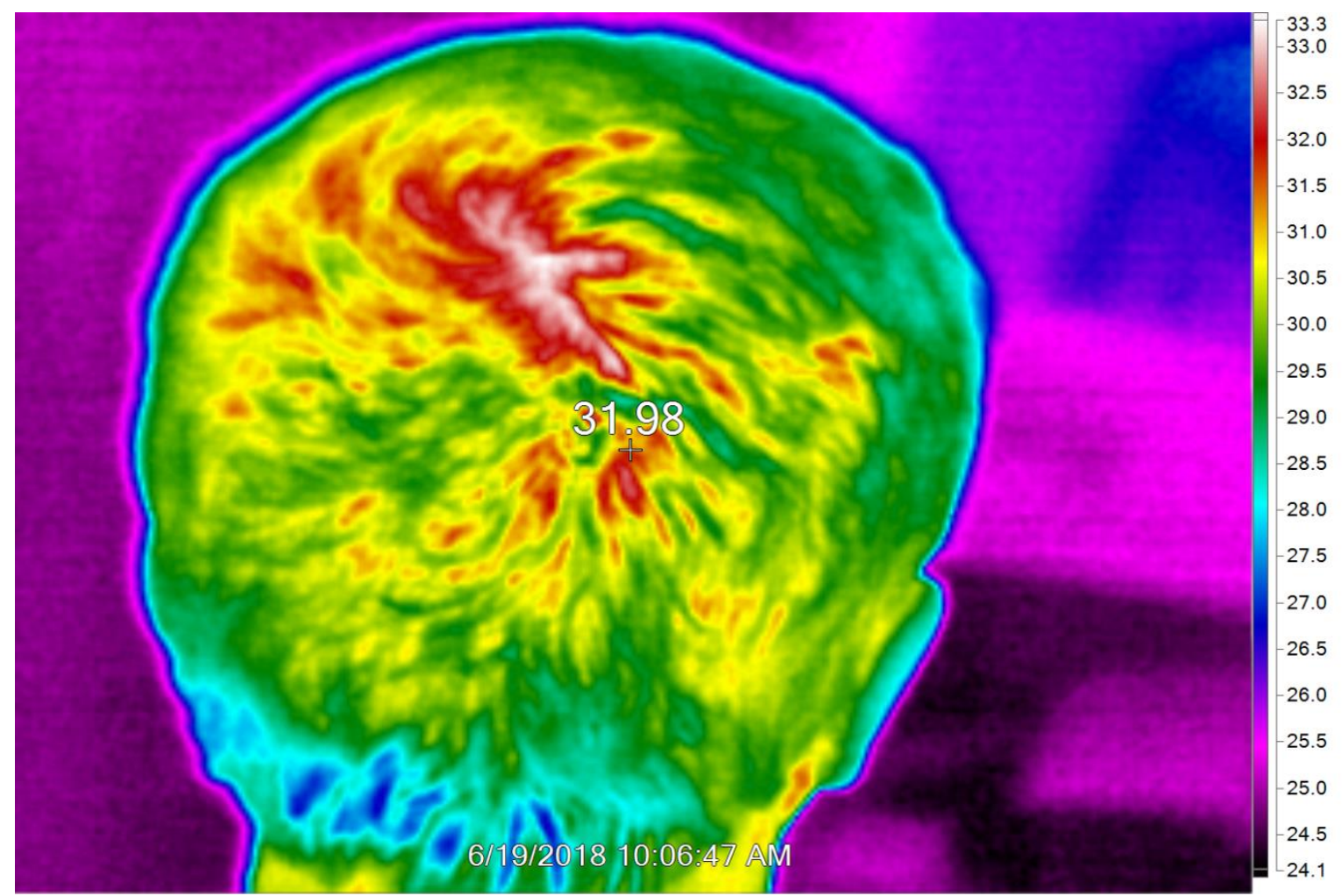

Figure 6. Second upper part of the head Thermo vision Camera state data, 2018 (The article's first author)

Source: Authors' own research. 


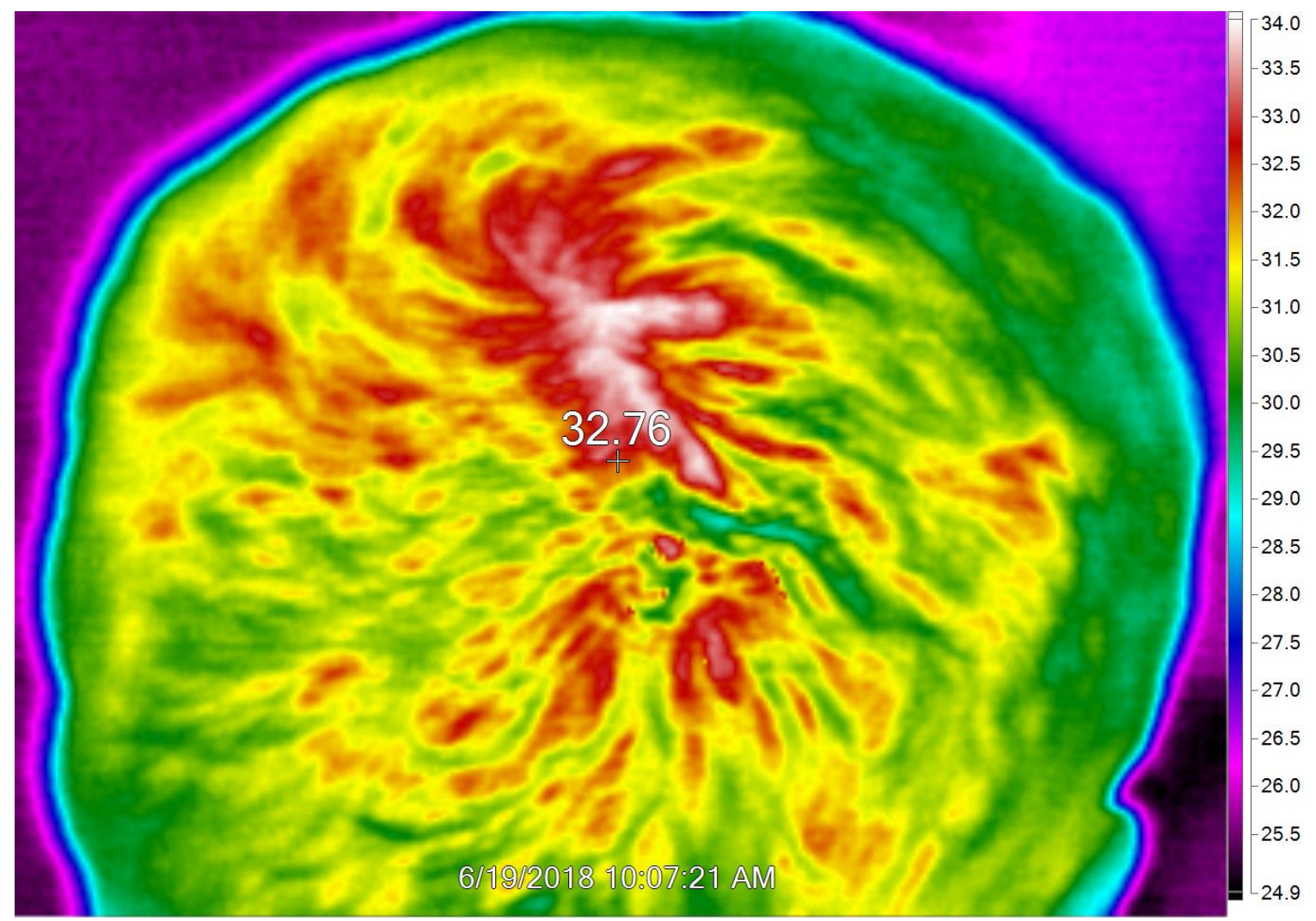

Figure 7. Third upper part of the head Thermo vision Camera state data, 2018 (The article's first author)

Source: Authors' own research

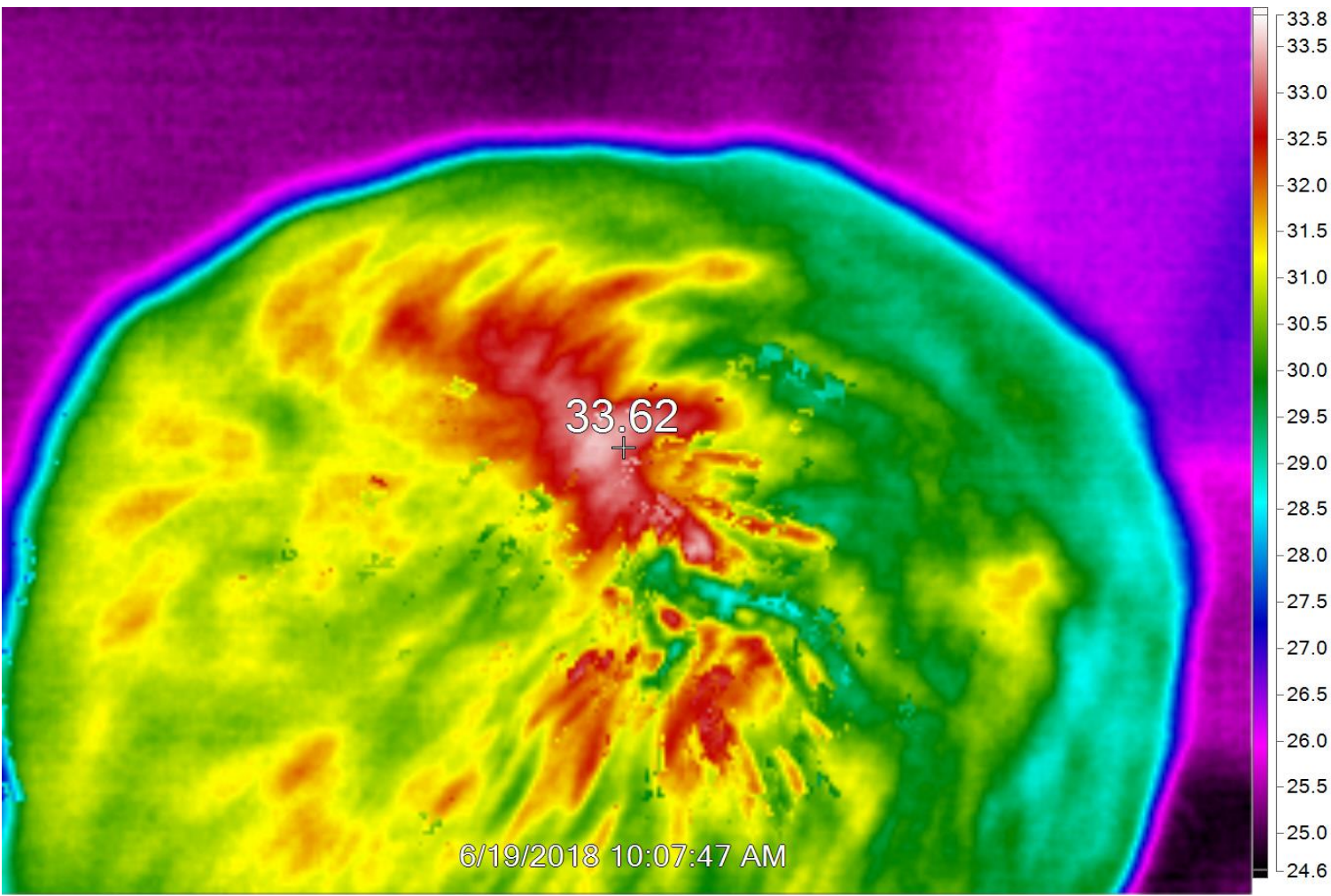

Figure 8. Fourth Upper part of the head Thermo vision Camera state data, 2018 (The article's first author)

Source: Authors' own research 


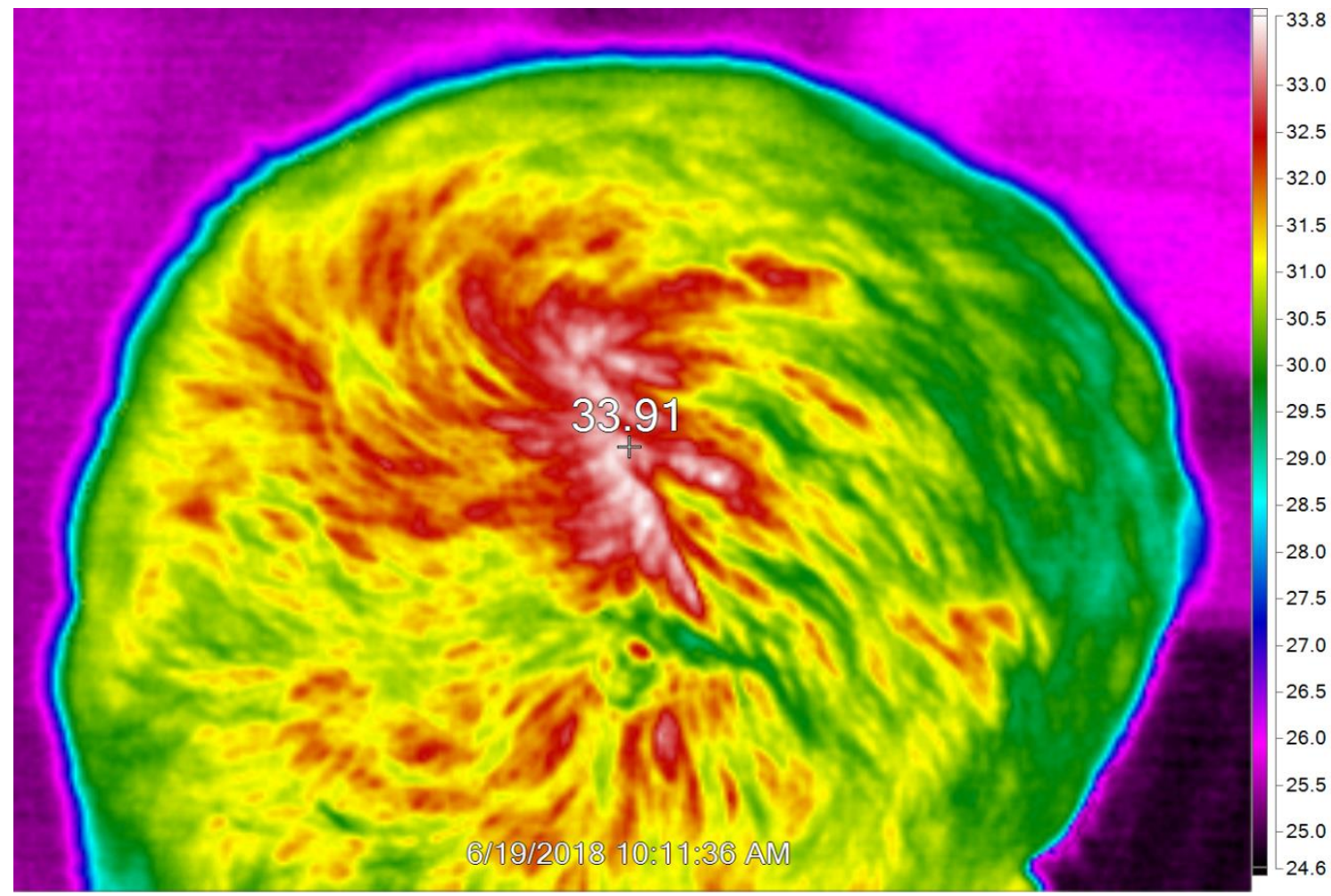

Figure 9. Fifth Upper part of the head Thermo Vision Camera state data, 2018 (The article's first author)

We present in Figure 10 the temperature variation over time in the upper part of the analyzed subject head. After one minute and a half, saturation is obtained.

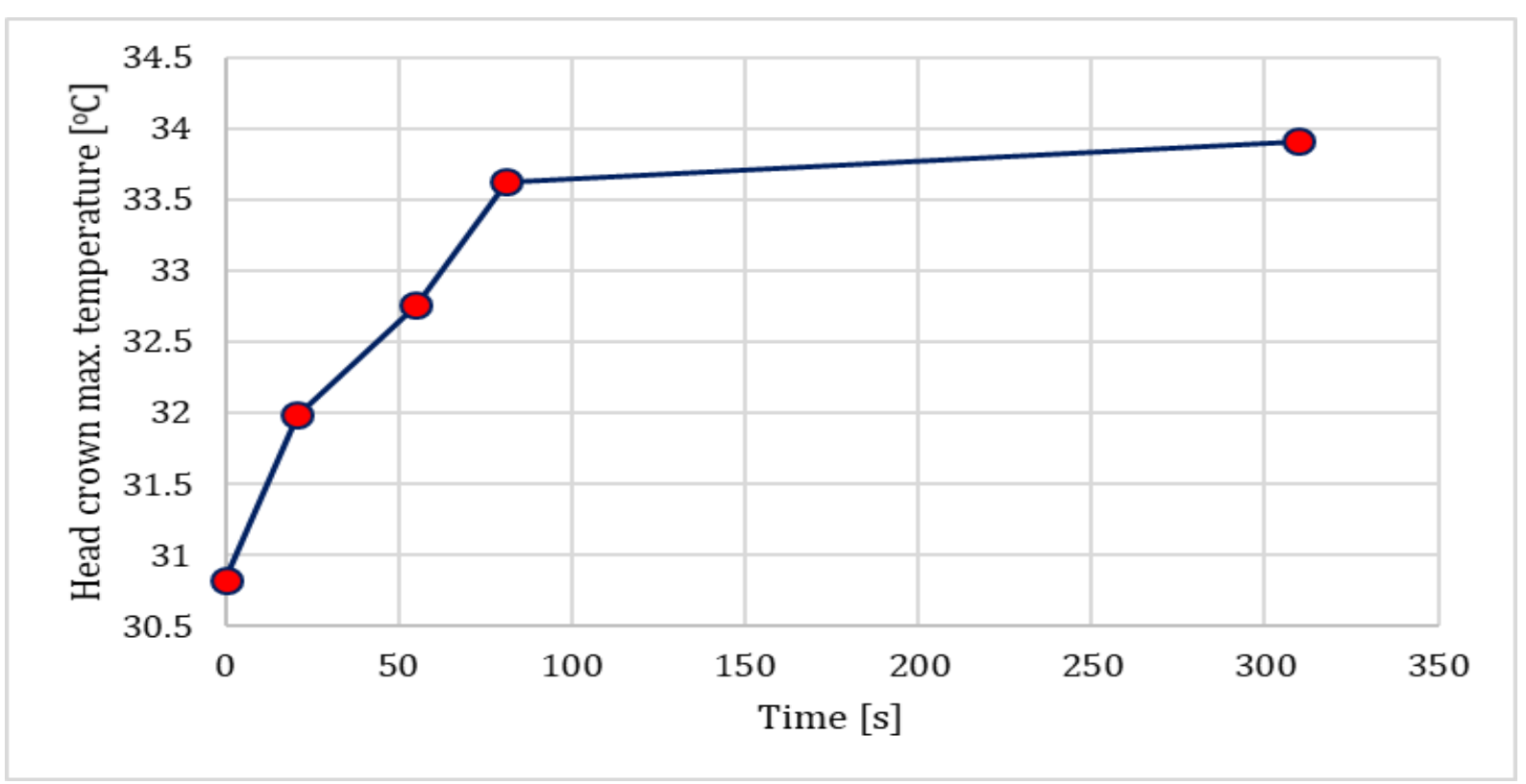

Figure10. The temperature variation due to the energy emissions over time, 2018 (The article's first author)

Source: Authors' own research

The considered starting time is 10:06:26 AM. The following moments of time represent the seconds elapsed since the starting time. 
After that, the temperature growing slows, as can be seen in Figure 10, from the fourth measurement made before $100 \mathrm{~s}$, until the last one made after over $300 \mathrm{~s}$.

The most important part of the experiment is highlighted during the first four measurements, where the temperature high growing cannot be a random one, produced by exterior causes. From a larger set of temperature measurements, the authors selected only these five graphic values, which present in Figure 10 the general temperature variation. Small oscilations due to the temporary cooling of the head were present in the entire set of measurements. Anyway, the authors decided that the general and important tendency of the temperature variation is good, as presented in Figure 10.

The importance of the second body energy centre was presented before by the first article author. There are reasons why the energy was sent beginning with this energy centre. These reasons go beyond the level of the physical body and by using specific knowledge, many human being problems can be solved [Mândrea \& Chirilă, 2017], [Mândrea, 2014], [Mândrea, 2011].

The third part of our article presents other five new measurements by employing the Bio Well Device, shown in the left part in Figure 11. These measurements show that we can repair ourselves, thus avoiding seeing doctors for every reason.
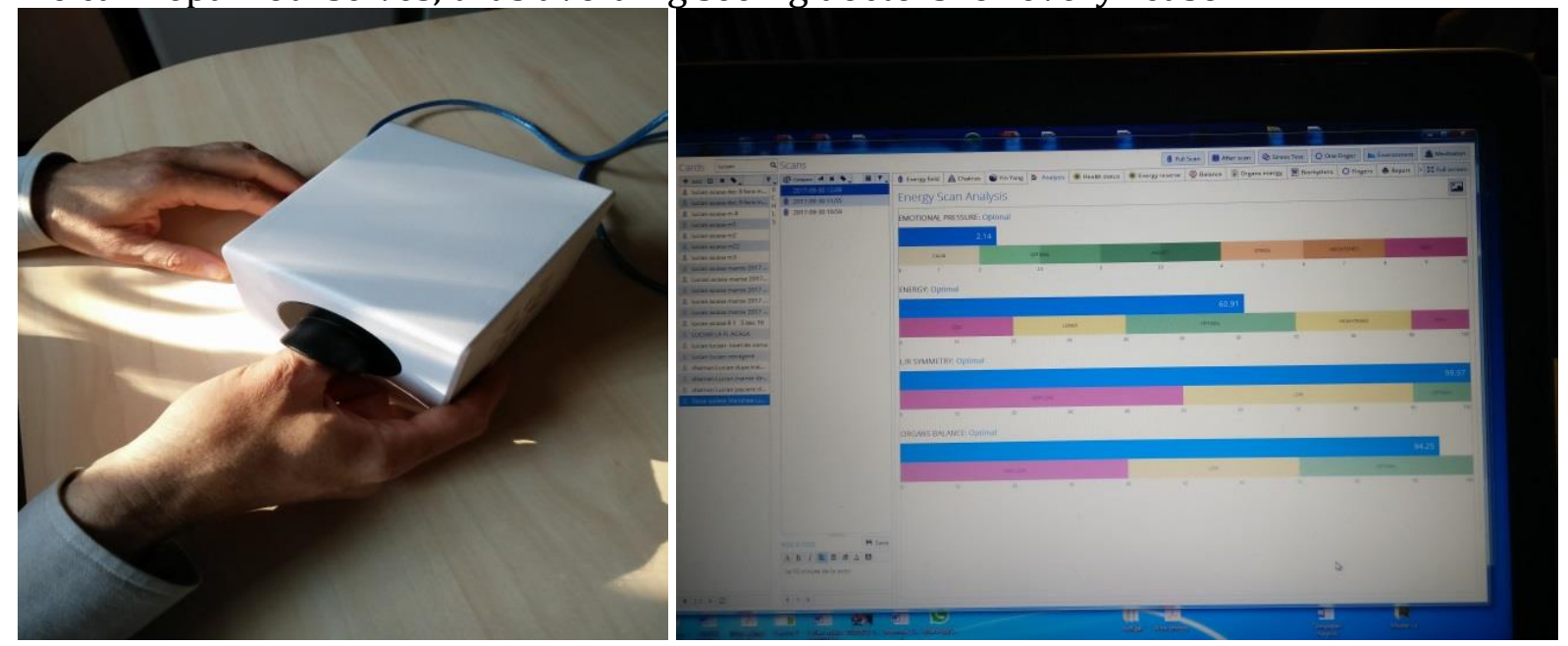

Figure 11. The Bio-Well device and the laptop screen with the measurement results

Source: Authors' own research

As can be seen in Figure 11, the subject must introduce each of his hand fingers into the white box. A small electric current excites the fingers which emit energy. Photos are taken every time with a very high-speed camera. The fingers aura and, also, the body aura are then presented as images on the laptop screen [Korotkov, 2007], [Yakovleva \& Korotkov, 2013], [Rubik, 2004], [Moss \& Johnson, 1973], [Kilner \& Cantab, 1911]. By associating the zones from the fingers with internal body organs as in the Chinese medicine, a health state can be presented with the help of the Bio Well device [Korotkov, 2002], [Korotkov, 2014].

The advantage of using such a device is, in general, a very short measurement time and the possibility to decide to see a certain doctor, according to what the radar following diagrams show you. If you cannot repair yourself, at least you already know the suffering gland or organ, according to their level of energy.

The emotional pressure evolution, also called the stress, the level of energy, the general balance or equilibrium of the body and also the organ balance evolution are presented in the next five measurements made in more than one hour, as in Figure 12: 


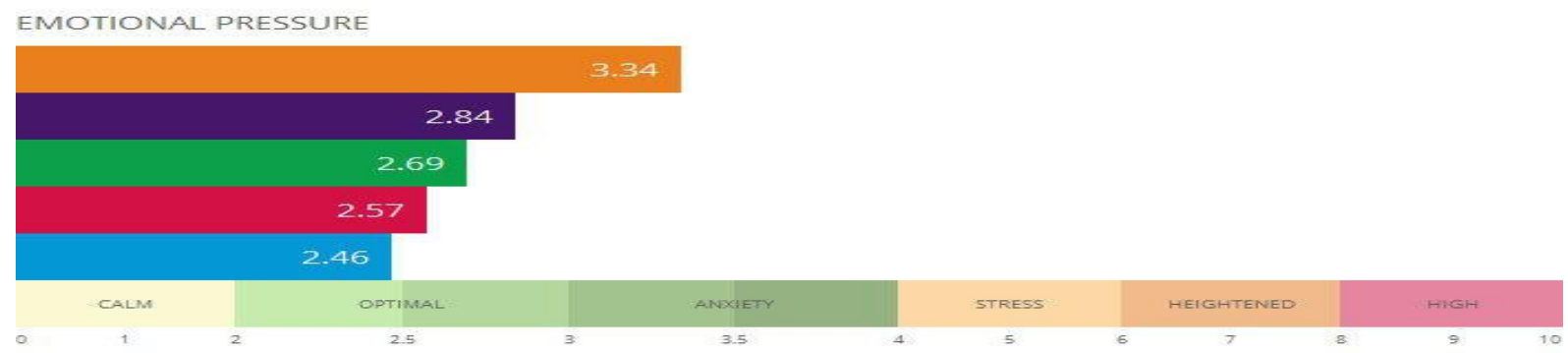

ENERGY

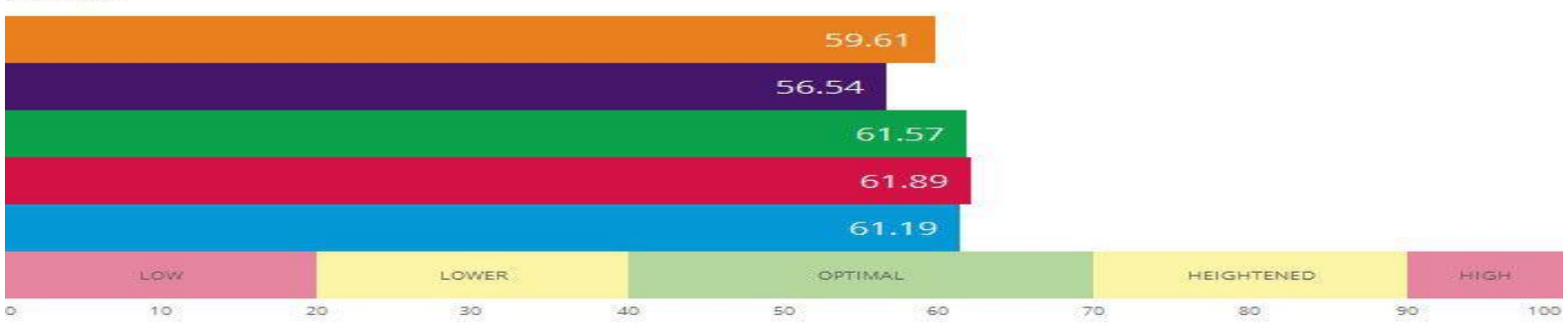

LIR SYMMETRY

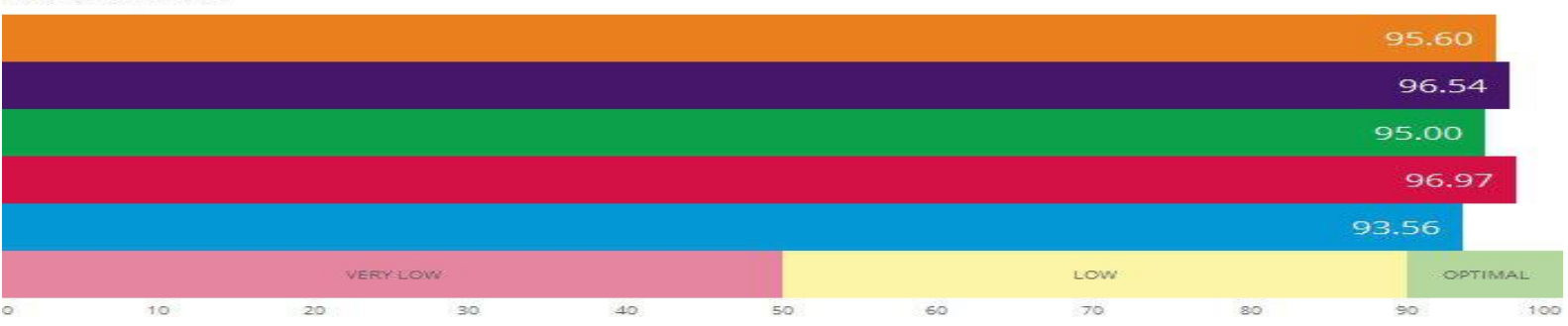

ORGANS BALANCE

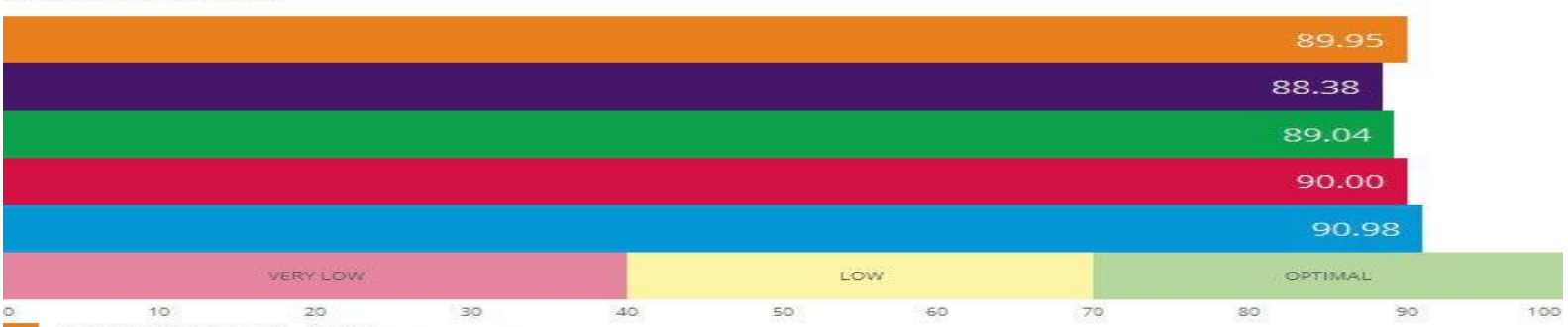

2018-02-25 11_10-lucian

2018-02-2511_34-lucian

2018-02-2511_55-lucian

2018-02-25 12_13-lucian

Figure12. Electro Photonic Imaging Device state data, recorded in February 2018 (The article's first author)

Source: Authors' own research

As can be seen, the stress diminishes in time with more than $26 \%$, from 3.34 to 2.46. The energy has small variations. Every time when the subject actioned on the thyroid, that means in the second and in the fourth measurement, the general symmetry increased to 96.54 on the row number 3 . Afterwards it increased to 96.97 , also, on the row number 3. The organs balance was generally improved until the end of the experiment to the value of 90.98 as in the row number 4 .

The first radar diagram (also called the eye bottom diagram) presents the health state of the analyzed subject, as shown in Figure 13. To be healthy, your personal line should be situated in the green sector of the disk. It is better if it is situated in the middle of this green zone. If your line is partially directed to the interior, then you have a tendency to become ill. If your line goes to the exterior of the zone, let us say to the white zone, then, a surplus of energy is present. As we shall see, in our case the things are moving generally in the green zone, with small exceptions. 

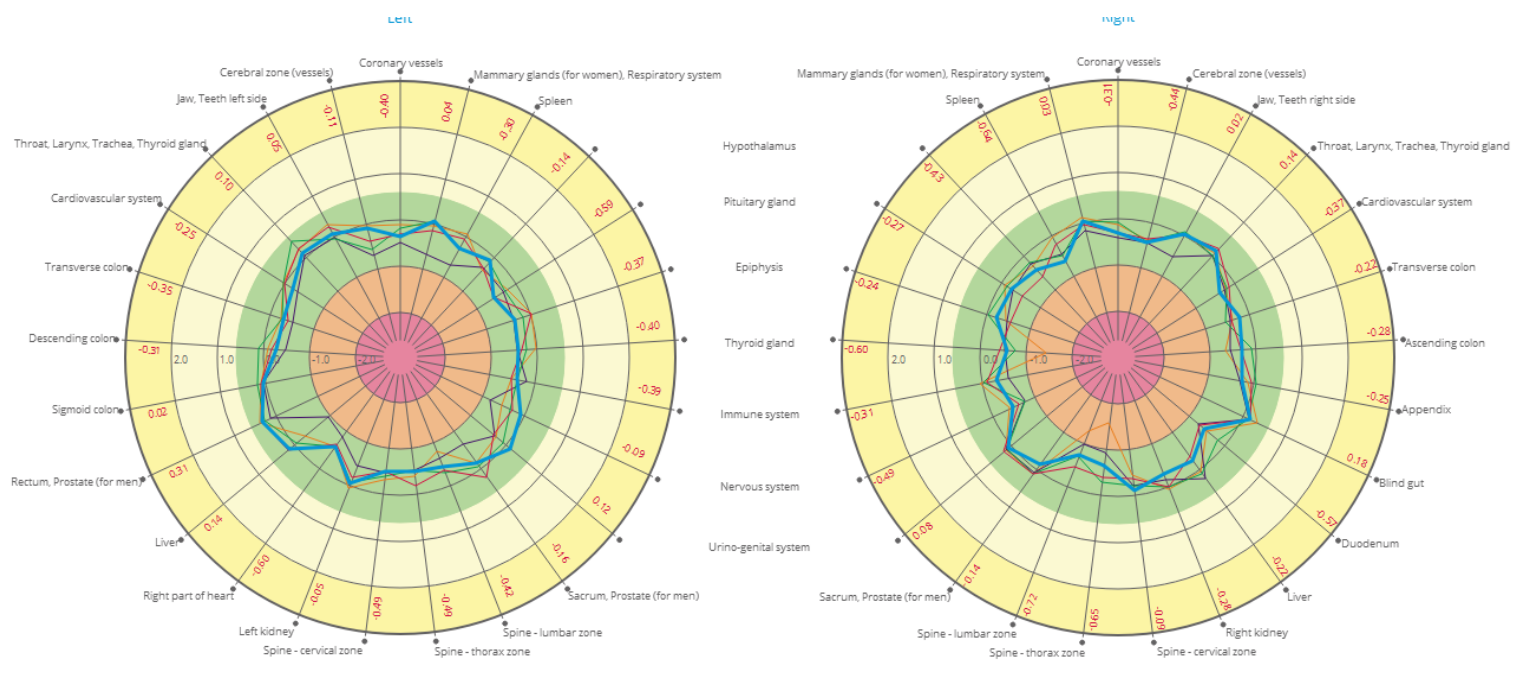

Figure13. The radar diagram of the subject energy and the health state at present (The article's first author)

Source: Authors' own research

The first health state of the subject at hours 11_10 on 2018-02-05, as the device records, is represented by the orange line. As we can see on the right side of the picture, this line enters into the orange disk at the level of the thyroid gland, which means a future possibility to become ill.

The orange disk zone represents the attention zone. Measures should be taken immediately.

As a consequence, the subject sent beams of energy from the zone of the abdomen to the thyroid. Supplementary actions were performed to attract the gland to its lowest position. The psychic balance was also improved to diminish the thyroid activity.

The first recovery is represented by the violet line at hours 11_34. The hysteresis of the body which strikes back is represented by the green line at hours 11_55.

The description of the hysteresis phenomenon was originally presented before by two authors of this article [Mândrea \& Curta, 2017].

The subject acted again and we can see the second recovery presented by the red line at hours 12_13.

The final equilibrium was established in the green disk, as it should be, shown by the blue line at hours 12_31.

So, in less than one hour and a half, the subject succeeded in bringing the energy of his thyroid gland to a normal value with good future expectations. A future doctor visit was cancelled.

The second radar diagram presents the future anticipated health state of the analyzed subject, since it refers to the so called the energy reserve, as it is shown in Figure 14.

The energy reserve represents, in other words, the availability in terms of the energy the body expects to have.

This diagram presents what the long future tendencies of the body will be like, so we can conclude that it warns us more than the diagram presented in Figure 13.

This diagram also certifies the present tendencies for the human body health. 


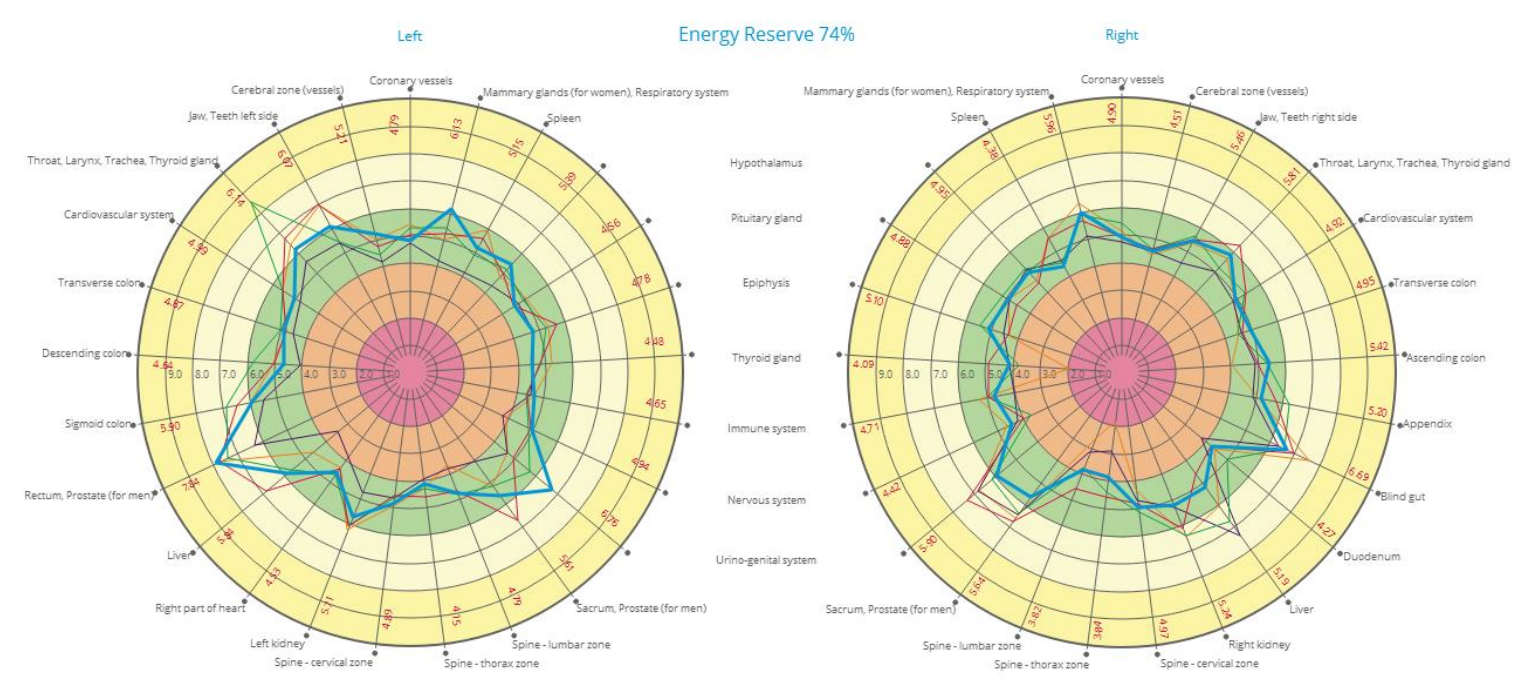

Figure14. The radar diagram of the subject energy reserve and the future health state (The article's first author)

Source: Authors' own research

If we look again at the right side of the picture, the future health state is really in danger because at the level of the thyroid gland the personal line touches even the violet zone, which means a future illness. It is indeed a more serious warning than in Figure 13. This thing justifies again that reparatory measures had to be taken immediately.

We can also follow in Figure 14 the same effects of the subject's previous actions, i.e. the first recovery represented by the violet line, the hysteresis by the green line, the second strong recovery by the red line and the final balance by the blue line in the green zone, which is the healthy zone.

In the next image we can see the so-called needles directed to the thyroid zone which signifies future dangers.
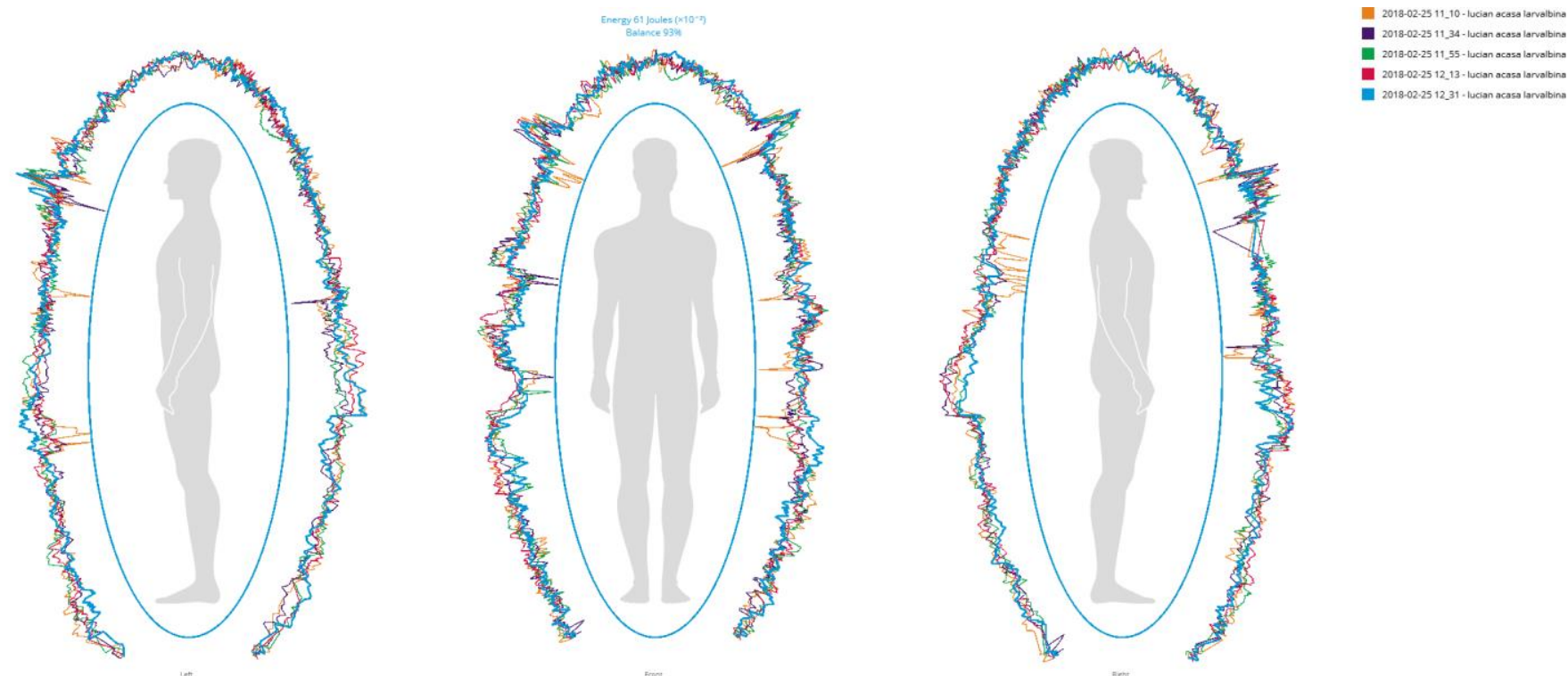

Figure15. The level of energy around the subject body with needles to the inside (The article's first author)

Source: Authors' own research 
The values of the thyroid gland energy during the five measurements were of $4.79,4.78,5.56,5.66$ and finally of 5.13 .

We can say that the subject could repair in a short time his thyroid functioning and succeeded in regaining the general body balance, as we can see in Figure 12, measurements number 2 and 4 .

The final subject state, as we can also see from Figure 12, shows a final lower stress value, of 2.46, of all of the five measurements, with all the other parameters in the optimal green zone.

Of course, other problems can appear, showed by the needles which are directed to other zones. They can have less importance and they can be eliminated after a while.

From our point of view, the major problem, that is the thyroid repair, was solved.

Special comments can be made at the end referring to the aspect of the subject's aura highlighted with the help of the Bio Well Device, corresponding to initial high value of the general balance of the article first author which was measured.

First of all, we will present the general aspect of the aura, left, front and right, in Figure 16.
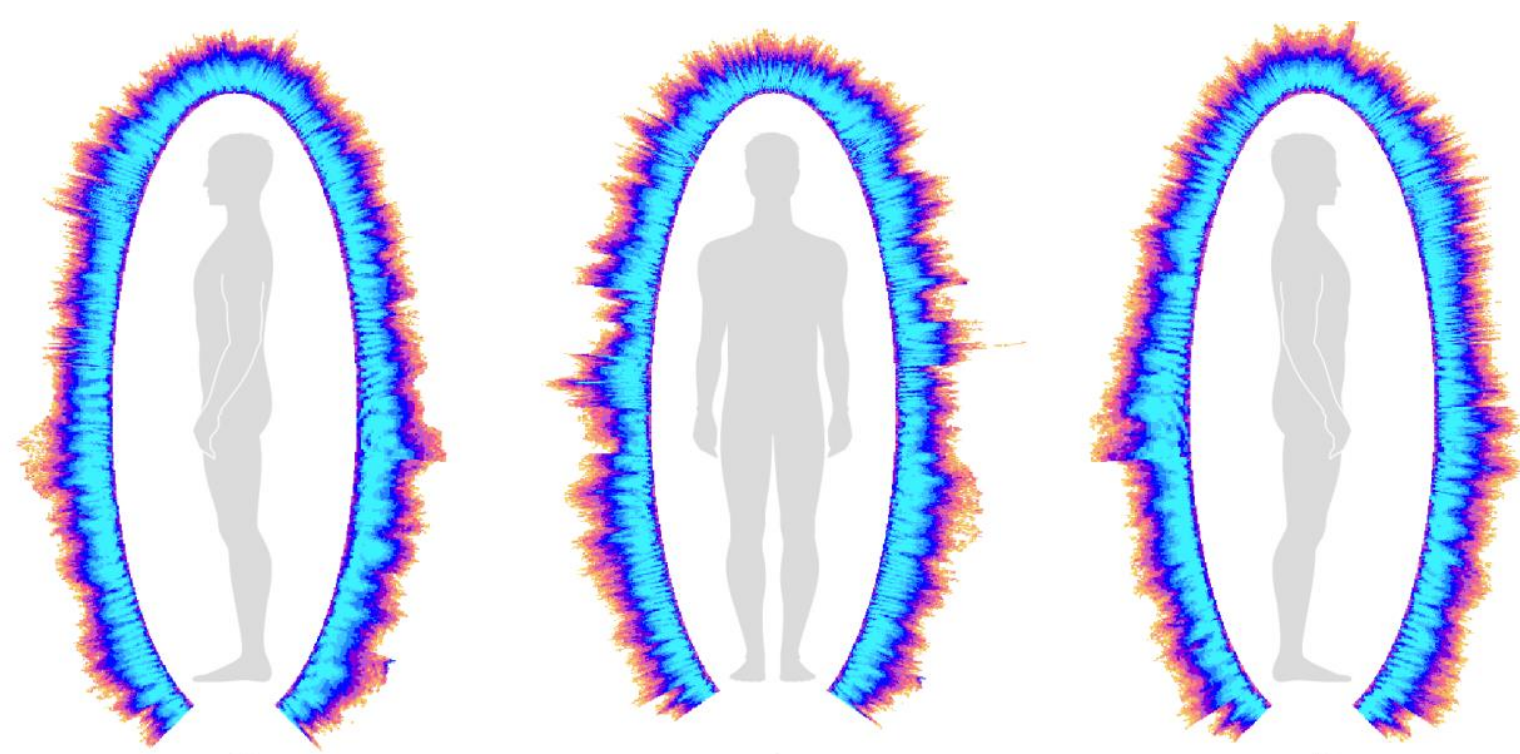

Figure 16. Electro Photonic Imaging Device energy shell, recorded in January 2018 (The article's first author)

Source: Authors' own research

We immediately observe, in Figure 16, that the energy shell has no breaks and is very consistent. Of course, it corresponds to the almost perfect equilibrium level of the body. Different information about the bioelectric field of the human body can be also obtained from [Becker \& Selden, 1985], [Bevk et al., 2000], [Boyers \& Tiller, 1973], [Chiang et al., 2005], [Cohen \& Popp, 1997], [Cohen \& Popp, 2003], [Connor \& Schwartz, 2007], [Devaraj et al., 1997], [Dobrin, 1975], [Dobrin, 1979], [Edwards, 1989], [Edwards, 1990], [Inaba, 1998], [Inaba, 2000].

We present, then, the fingers aspect of the aura, one by one, as in Figure 17. The aspect of every finger energy field looks similar with the general energy field from Figure 16. They are also very consistent and have no breaks.

Every image has sectors around the fingers which correspond to different organs and glands in the body, so they offer the possibility to see immediately if something is wrong from the energy viewpoint. 


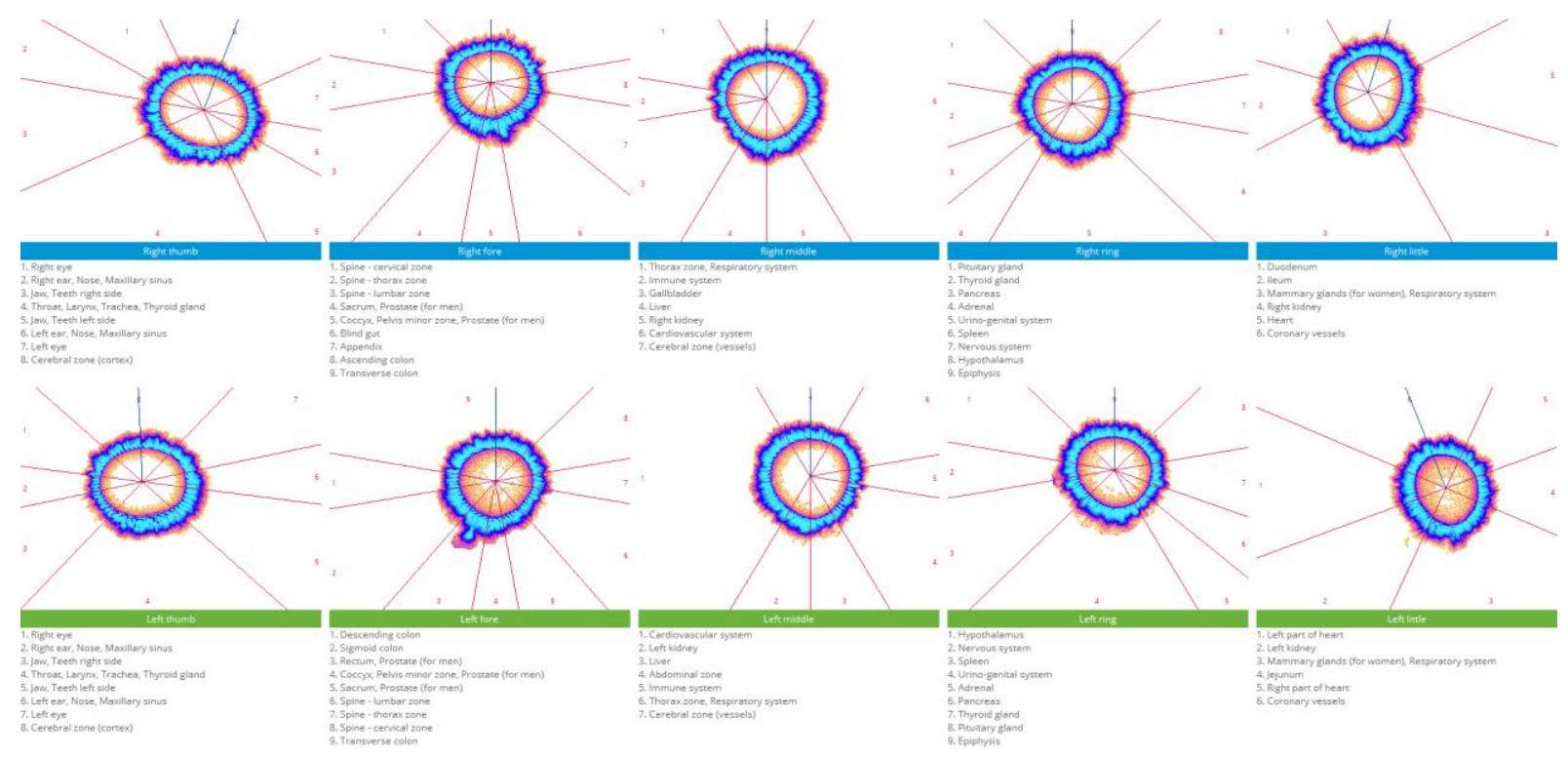

PICBE | 25

Figure 17. Electro Photonic Imaging Device fingers energy shell, recorded in January 2018 (The article's first author)

Source: Authors' own research

\section{Conclusions}

The authors presented three sets of original results of high importance for the functioning of the human being. They consider that an excellent personal state can be obtained in principle by everybody quite often.

Using the Bio Well Device, the authors could show that a very high general balance of the human being can be obtained as in the first part of the article. With continuous efforts, this very good equilibrium can be even maintained in time.

With the help of a completely original set of temperature variation measurements, the results presented by means of the Thermo Vision Camera reveal what a living being can do with the own body, the physical and the energetic one.

Many things can be possible in terms of improving our human being general functioning, as shown in the second part of the article.

Even if unpleasant or potentially damaging situations appear we are able to eliminate them by our own means, as shown in the third part of the article. The usage of the Bio Well Device is a very helpful one because the results show us very quickly what happens with a human being and offer a lot of important parameters.

The domain of business excellence is one of the domains in which an individual must be always in a good shape to succeed. So especially in this field these researches are very important.

It is preferable for a businessman to learn always how to improve constantly the personal state in order to have success. Reading materials like this one, a businessman can understand more about the human being functioning and what a human being can realize with the own means.

In fact this is the practical importance of this research for the domain of business excellence.

As a final conclusion, a superior human being energy control can be achieved in order to increase our chances so as to maintain our health and improve our performances, not only in business, but also in life in general.

We can be confident that we can do more to better our human being functioning. 


\section{References}

Becker R. O., Selden G., (1985) The body electric: electromagnetism and the foundation of life, New York City, William Morrow and Company.

Bevk M., Kononenko K., Zrimek T. (2000) Relation between Energetic Diagnoses and DV Images, from the proceedings of the New Science of Consciousness, Ljublana, Russia, October 2000.

Boyers D. G., Tiller W. A. (1973) Corona discharge photography, Journal of Applied Physics 44:3102.

Chiang L. H., Wah K. P., Ghista D. (2005) Bioenergy based medical diagnostic application based on gas discharge visualization, Conference Proceedings IEEE Eng. Med. Biol. Soc. 2:1533.

Cohen S, Popp F. A. (1997) Bio photon emission of the human body, J. Photochem Photobiol B., Biol. 40:187.

Cohen S, Popp F. A. (2003) Bio photon emission of the human body, Indian J Exp. Biol. 41(5):440.

Connor M., Schwartz G. (2007) Measuring ELF magnetic fields, In Schwartz G, editor: Research Findings at the University of Arizona Center for Frontier Medicine in Bio field Science: A Summary Report. Available at: http://lach.web.arizona.edu/CFMBS_Report.pdf , Accessed September 2007.

Devaraj B., Usa M., Inaba H. (1997) Bio photons: Ultra weak light emission from living systems, Curr. Opin. Solid State Mater Sci. 2:188.

Dobrin R. et al. (1975) Experimental measurements of the human energy field, In Krippner S., Rubin D., editors: The energies of consciousness, New York City, Gordon and Breach.

Dobrin R. et al. (1979) Experimental measurements of the human energy field, In Krippner S., editor: Psycho-energetic systems: the interface of consciousness, energy, and matter, New York City, Gordon and Breach.

Edwards R. et al. (1989) Light emission from the human body, Complement Med. Res. 3:16.

Edwards R. et al. (1990) Measurements of human bioluminescence, acupuncture, and electrotherapeutics, Res. Int. J. 15:85.

Fluke (2013) Ti300 - Thermal Imager - User's Manual, Rev.3 2/17, Fluke® Corporation, September 2013.

Inaba H. (1998) Measurement of ultra-weak bio photonic information, Proc. Inst. Electrostat. Japan 22:245.

Inaba H. (2000) Measurement of bio photons from human body, J Int. Soc. Life Inf. Sci. 18:448.

Kilner W.J., Cantab M.B. (1911) The Human Atmosphere or The Aura Made Visible by the Aid of Chemical Screens, Rebman Company, New York, 362 pg.

Korotkov, K. G. (2002) Human Energy Field, Study with GDV Bio-Electronography, BACKBONE PUBLISHING Co., USA, ISBN 096443119X.

Korotkov, K. G. (2007) Diagnosis and monitoring of the human energy-informational state and analysis of subtle energies, applying Gas Discharge Visualization technique, based on the Kirlian method, Saint-Petersburg Technical University SPIFMO, Russia, http://gdv-energiecoaching.be/wp-content/uploads/05/2007 GDV-Overview-article.pdf. 
Korotkov, K. G. (2014) Energy Fields Electro-Photonic Analysis in Humans and Nature. $2^{\text {nd }}$ Edition, Create Space Independent Publishing Platform, April 21.

Mândrea, L. (2011) Comportamentul sufletului în corpul uman, The Behaviour of the Soul in the Human Body, Editura Tornada, Tornada Publishing House, Bucharest 2011.

Mândrea, L. (2014) Percepții extrasenzoriale, Sufletul în corpul uman, Extra-sensorial Perceptions, The Soul in the Human Body, Editura Tornada, Tornada Publishing House, Bucharest 2014.

Mândrea, L., Costea, M., Torp, A. (2015) The Energy Emissions Produced by the Human Being and their Practical Use, THE $9^{\text {th }}$ INTERNATIONAL SYMPOSIUM ON ADVANCED TOPICS IN ELECTRICAL ENGINEERING, May 7-9, 2015, Bucharest, Romania, 978-1-4799-7514-3/15/\$31.00 (C)2015 IEEE, P.260-264.

Mândrea, L., Torp A. (2016) Energia umană și posibilități de remediere proprii, Human Energy and Self Remedy Possibilities, EUB International Conference, April 4-5, Bucharest, Romania.

Mândrea, L., Chirilă, A. (2017) The Complete Human Being, Energy and Soul, the $11^{\text {th }}$ International Conference on Business Excellence, Strategies, Complexity and Energy in Changing Times, 30-31 March 2017, Bucharest, Romania.

Mândrea, L., Chirilă, A. (2017) The Complete Human Being, Energy and Soul, Proceedings of the International Conference on Business Excellence, published by De Gruyter Open, 2017-08-26, DOI: https://doi.org/10.1515/picbe-2017-0046, pp. 427-436, Volume 11, Issue 1, ISSN 2558-9652.

Mândrea, L., Curta I. (2017) The Modification of the Energy Level of the Human Being, Influences on the Psychic State and Health, A XVII-a Conferință internațională multidisciplinară "Profesorul Dorin PAVEL - fondatorul hidroenergeticii românești", The $17^{\text {th }}$ International Multidisciplinary Conference "Professor Dorin PAVEL", Sebeș-Alba, 2-3 iunie 2017, pg. 117-124, ISSN 2067-7138.

Mândrea L, Curta I. (2017) The Hysteresis Phenomenon in the Human Bio-Energetic Field, THE $10^{\text {th }}$ INTERNATIONAL SYMPOSIUM ON ADVANCED TOPICS IN ELECTRICAL ENGINEERING, March 23-25, 2017, Bucharest, Romania.

Mândrea, L., Curta I., Marosy Z. (2018) High Energy, Increased Balance and Self Control, Necessary Conditions for Performance and a Good Health, The 12-th International Conference on Business Excellence, Innovation and Sustainability in a Turbulent Economic Environment, 22-23 march 2018, Bucharest, Romania.

Moss T., Johnson K. (1973) Bio-plasma of Corona Discharge, in S. Krippner, D. Rubin, Galaxies of Life: The Human Aura in Acupuncture and Kirlian photography, Gordon and Breach Science Publishers, Inc.

Rubik B., (2004) Scientific Analysis of the Human Aura. In: In K. Korotkov (ed.): Measuring Energy Fields State of the Science, Fair Lawn, NJ., Backbone, pg. 157170.

Torp A. (2018) Research into a HR assessment method based on the human energy profile, The 12-th International Conference on Business Excellence, Innovation and Sustainability in a Turbulent Economic Environment, 22-23 march 2018, Bucharest, Romania.

Yakovleva, E., Korotkov, K. G. (2013) Electro-Photonic Analysis in Medicine. GDV Bioelectro-graph Research, ISBN 978-1481932981. 